\title{
Preface
}

\section{Theme issue on hydromechanics in geology and geotechnics}

\author{
Ove Stephansson, Guest Editor
}

Over the last two decades, substantial efforts have been made in theoretical and experimental studies of the effects of coupling between hydrologic flow and mechanical deformation (hydromechanical or HM coupling) in geologic systems and on the implications of HM coupling for engineering applications. Much of the impetus behind these efforts is the concern over environment and natural resources, including issues such as water extraction and related subsidence, pollution and solute transport, geothermal-energy extraction, cold-water injection for secondary recovery from deep petroleum reservoirs, microearthquakes induced by fluid injection and fluid transport from storage and deposition of radioactive waste and spent nuclear fuel. There is a growing consensus that many of the geological processes can be fully understood only by considering HM coupling. Shearing, faulting, seismicity, and hydraulic fracturing are manifestations of flow and deformation coupling in the Earth's crust, while settlement, landslides, slope instability, and debris flow are examples of HM-coupled phenomena in soils.

The term hydromechanical coupling or hydromechanics describes the interaction between hydraulic and mechanical processes in soil and rock. Such media contain pores and fractures, which can be filled with different fluids, and they are deformable. A fluid-saturated porous medium or rock fracture will deform because of either changes in the external load or changes in the internal pore pressure. Increased external load means that the pore volume and the bulk volume of the medium change. If the external load is applied slowly, the fluid may have time to escape slowly and the pressure can remain relatively constant. If, on the other hand, the load is applied quickly, the pore fluid pressure will increase. The first situation is called a drained HM response and the second an undrained HM response. A reduction in fluid pressure

Published online: 18 January 2003

(C) Springer-Verlag 2003

O. Stephansson $(\varangle)$

GeoForschungsZentrum,

Telegrafenberg, 14473 Potsdam, Germany

e-mail: ove@gfz-potsdam.de and/or fluid mass causes settlement of the porous media. This is usually followed by a reduction in pore and bulk volume, which manifests itself in compaction and subsidence.

This theme issue on hydromechanical coupling comprises ten articles. Two of these are topical overviews (Rutqvist and Stephansson 2003; Neuzil 2003). Four are site descriptions related to subsidence, soil and rock failure, and groundwater extraction (Lewis et al.; Zangerl et al.; Alonso et al. 2003; Barnichon and Volckaert 2003). Two contributions deal with HM coupling during experimental and tectonic rock deformation, respectively (Heiland 2003; Morin and Savage 2003). One deals with hydrogeologic and geochemical responses to seismic stresses (Woith et al. 2003), and one deals with fracture growth and fluid flow (Gudmundsson et al.2003).

Rutqvist and Stephansson (2003) provide an overview of HM couplings in fractured rocks. The paper is structured in the sequence: observations, analysis, and applications, and presents historical milestones about the development of the mechanical and hydraulic processes in fractured rocks. In the early 1960s, hydromechanical coupling in fractured rocks started to receive wide attention following a series of events induced by human activities including dam failures, landslides, and injection-induced earthquakes. Today, coupled HM analysis is being applied to many geological engineering practices like well testing, oil and gas exploration and extraction, geothermal energy, nuclear-waste disposal, and deep-well injection of liquid waste. The authors describe the lessons learned from these applications and draw some general conclusions about the most important parameters for the stress-permeability relationship of single-rock fractures and fractured-rock masses.

Neuzil (2003) presents a comprehensive and clearly written overview of HM coupling in geological processes. This contribution is highly recommended as an introduction to the subject. It presents the early concepts of HM coupling and its importance for the understanding of deformation and failure of geological materials. The theoretical development of poroelasticity from Biot's work in the early 1940s (see references in Neuzil 2003) to modern numerical methods is presented together with a very clear and concise development of the governing 
equations relating changes in stress, fluid pressure, and temperature. Elastoplastic and viscoelastic strains in rocks and sediments are also introduced. One section of this contribution is devoted to 'pragmatism in analysis' and describes the most common simplifications used in studying HM couplings in geological systems. The manifestations of flow and deformation coupling in geological systems are presented in two different sections: (1) the effect of deformation on fluid regimes and (2) the effects of fluids on deformation. Sediment compaction, erosional decompaction, tectonics, and earth tides are examples of the first group and arrested compaction, natural hydrofracturing, shearing, faulting, and seismicity are typical examples of the second group. In his concluding remarks, Neuzil (2003) discusses the importance of HM coupling and how this is understood and analyzed in geology.

To a large extent, flow of water in rock masses is determined by the distribution of interconnected fractures and the way in which their apertures respond to the applied stress field. Gudmundsson et al. (2003) have studied the effects of linking up of discontinuities on fracture growth and groundwater flow. Their contribution has three principal aims: (1) to summarize field data on extensional fractures and shear fractures as a basis for modeling; (2) to develop analytical and numerical models of extensional and shear fractures; and (3) to present general analytical models on fluid flow in fractures using field data and results from modeling. Field examples of extensional and shear fractures are taken from Iceland, England, and Norway. A boundary-element formulation and the program BESY have been applied to simulate mode I extension hydrofractures with linear variation of pressure from $10 \mathrm{MPa}$ in the center of the fracture and zero pressure at the fracture tip. Models with different numbers and orientation of joints approached by hydrofractures are studied. Linkage of offset joints into interconnected fracture sets that may develop into shear fractures and later into major faults is another group of models presented. Gudmundsson et al. (2003) have extended the cubic law for volumetric groundwater flow to include an excess pressure gradient in the flow direction. Its application to fluid flow in dipping faults and a comparison with an analytical formulation of aperture variation of a hydrofracture show that the aperture is larger where the hydrofracture dissects soft layers compared to where it intersects stiff layers.

Morin and Savage (2003) examine the link between stress and groundwater flow based upon the analysis and interpretation of geophysical logs, aquifer tests, and packer tests obtained in water wells at two sites in the US that are distinguished by different rock types and different topography and state of stress. The first study area is the northeastern parts of the Newark Basin at the border of Pennsylvania and New Jersey. From fluid-property $\operatorname{logs}$ and flowmeter measurements it was found that the bedding planes of the late Triassic and early Jurassic fluvial and lacustrine sediments are highly transmissive near the surface. With increasing depth and higher verti- cal stress, these planes become less dominant and sets of steeply dipping, but less transmissive fractures begin to become more influential in controlling fluid flow (cf. the discussion about the influence of fracture stiffness and stress state in the contribution by Rutqvist and Stephansson 2003). These fractures generally strike parallel to the current regional maximum principal stress. Results from the log analyses can be interpreted within the context of the tectonic setting and existing state of stress to develop an understanding of the groundwater flow system in large parts of the Newark Basin. The second site for the hydromechanical case study by Morin and Savage (2003) is situated in a valley along the southern edge of the Davis Mountains in west Texas. The rocks underlying shallow alluvium are mostly volcanic rocks of Tertiary age. From geophysical logs recorded in six wells located in an east-west trending valley setting of the area, a distinction can be made between the hydrologic properties of two water-producing categories of fractures: an upper and lower contact bounding a dense trachyte unit between 100 and $150 \mathrm{~m}$ depth and a deeper interval of highly fractured basalt. In this extensional stress regime, the vertical principal stress corresponds to the maximum principal stress and the least principal stress is known to be subparallel to the valley axis. An exchange of the maximum and minimum principal stress with depth at the valley side is known from stress-induced breakouts in one of the six wells in the area. The hydrological significance of the stress state in the valley is examined by means of the stress invariants and their relation to the Drucker-Prager failure criterion. The superposition of tectonically and topographically induced stresses in the valley has propped open fractures beyond a percolation threshold to form an interconnected and permeable network, rather than discrete, large fractures. The two cases presented by Morin and Savage (2003) demonstrate how the virgin state of stress and tectonics impact the hydrologic characteristics of aquifers and how this can be traced by analysis of geophysical-log data from wells and from knowledge of the state of stress in the area.

Shearing, faulting, and seismicity are discussed by Neuzil (2003) as examples of how HM coupling manifests itself in the crust. It is known that relatively small pressure perturbations can trigger earthquakes. It is also known that earthquakes affect hydrogeological systems such that most reported cases describe changes of water level and temperature in wells. Only a few cases are reported in the literature about co- and post-seismic response of groundwater chemistry. In their contribution, Woith et al. (2003) describe the latest findings from the international earthquake research project READINESS (Realtime Data Information Network in Earth Sciences) where water level, water temperature, specific electrical conductivity, $\mathrm{pH}$, and radon are monitored continuously at selected sites in the eastern Mediterranean region. At one of four sites in Turkey and Armenia, the monitoring revealed a 7\% co- and post-seismic drop in the specific electrical conductivity of an artesian mineral water well, 
while no changes were observed in the other three sites despite their closer location to the Izmit and Duzce earthquakes of 1999. The change in conductivity is thought to be triggered by passing seismic waves that cause local pore-pressure increases according to the mechanism of advective overpressure. Woith et al. (2003) reach the conclusion that the seismic response of a hydrogeologic system seems to depend on the site characteristics rather than the nature of the earthquake.

Permeability is one of the most important parameters in studies of HM coupling of geologic processes and man-induced activities related to rock and geotechnics. Laboratory experiments and field tests have shown that permeability of soils and rocks varies over several orders of magnitude depending on fluid properties, confinement, and applied load path and stress magnitude. Heiland (2003) presents an overview of laboratory testing of permeability for sandstones, granites and rock salt during rock deformation. Results for the most common stress paths are presented in diagrams of permeability versus applied pressure (hydrostatic compression), differential stress (triaxial compression), and effective axial stress (uniaxial strain test), respectively. The permeability evolution of high-porosity rocks under these stress paths shows continuous decreasing permeability with increasing confinement. Only when the initial pores collapse and grain crushing starts, does the permeability undergo a sharp decline. For low-porosity rocks, a similar reduction in permeability is obtained for increasing confinement to a point where the rock starts to show dilatant deformation and pore-volume increases and the permeability starts to increase. Heiland (2003) states that for reservoir production and depletion scenarios in porous rocks, a continuously decreasing permeability in the source rock can be assumed. In the case of underground waste repositories in crystalline rocks (granites and gneisses) and rock salt, the deep-seated location of the repository and the heat loading in the case of radioactive waste can cause high differential stress, which might lead to microfracturing and joint displacement, leading to rock-mass permeability increases.

The geological deformation of oil and gas reservoirs has been of concern to petroleum engineers ever since the discovery in the mid-1980s of a large subsidence bowl in the Ekofisk field of the North Sea. Understanding of seafloor subsidence due to sediment decompression remains unresolved despite large investments and input of resources. Lewis et al. (2003) present a worldwide review of reservoir subsidence phenomena and use coupled continuum modeling of multiphase poroelasticity applied to three-dimensional numerical simulations of oil and gas reservoirs. In the multicomponent model, it is assumed that there is water, heavy crude oil, and an organic gas phase coexisting in the porous rock. Applying multiphase poroelasticity, pore compressibility, and the effective stress changes in the modeling of the Ekofisk oil reservoir in the North Sea, the compaction profile of the reservoir and the subsidence bowl of the sea bottom are simulated. Analysis of the computation reveals that coupled
HM modeling is needed for this type of problem and, more specifically, that due to the downward movement of the overburden, oil migration occurs from the crest towards the flanks of the dome structure of the Ekofisk field. In addition, the overburden layers experience bending, which causes significant horizontal movements of the surrounding formations, often leading to casing damage and wellbore failure during drilling. The authors have demonstrated that consideration of the correct physical processes is essential for improving the reliability of production forecasting and for optimizing the simulation of structurally complicated hydrocarbon reservoirs.

In most cases, ground settlement is caused by human activities or disturbances in soft rocks. In this collection of papers, Zangerl et al. (2003) present the interesting observation of $12-\mathrm{cm}$ vertical settlement in fractured crystalline rocks several hundred meters above the Gotthard highway tunnel in central Switzerland. The settlement is caused by large-scale consolidation of fractures resulting from groundwater drainage and pore-pressure change following the tunnel construction. Maximum settlement and high inflow rates to the tunnel were measured along sections consisting of heavily fractured granitic gneiss. The inflow occurred along a 3-km-long section of the tunnel and the settlement trough measured about $10 \mathrm{~km}$ in length. The settlement was deduced from repeated geodetic leveling measurements. Zangerl et al. (2003) present results from four different modeling strategies to explain the settlement in the hard rocks. Distinct-element modeling with the UDEC code and application of known geometry of fractures and realistic material properties could not explain the magnitude of settlement. A maximum deformation of $3.6 \mathrm{~cm}$ could be obtained in coupled-HM modeling with linear poroelasticity when vertical fractures dominated. Additional model developments are needed to incorporate inclined fractures and fracture zones together with other constitutive models and input parameters for the intact rocks.

Fluid pressure controls fracturing, shear failures, and shear slippage in soil and rock, and these processes can cause many different types of geological hazards. Landslides and flowslides in overconsolidated soils are in this group of hazards. Alonso and Gens (2003) describe the results of simulating a large flowslide in overconsolidated clays that caused full destruction of three suburbs of the city of Ancona in eastern Italy in December 1982. The authors present the result of a European Community programme on climatology and natural hazards where a group of European institutions instrumented slopes near the one that failed in 1982 and analyzed their stability in the context of Mediterranean climate. The authors present the results of laboratory testing and HM modeling of the effect of rainfall on the stability of the slope. Two deformation mechanisms have been identified in the slope study: a creep-type deformation along the full depth of the soil, and a surface planar slide. Alonso and Gens (2003) reach the conclusion that permeability and water retention are fundamental properties in slope-stability analysis and that this is often overlooked in slope analyses. 
The field of underground storage and deposition of radioactive waste and spent fuel is one of the important applications of HM coupling. This was realized at an early stage of testing and modeling of the rock-mass response to excavation and long-term drainage in several underground laboratories and test sites worldwide, and it is independent of rock type. Barnichon and Volckaert (2003) describe the observed failure during the excavation of the shaft annexes of the Test Drift in the Boom marine clay of the Underground Research Laboratory at the Mol site in Belgium. A second shaft was excavated in 1998-99 and concrete lining was installed. During the excavation, some fracturing was observed and new fractures developed as a test chamber was excavated adjacent to the shaft. Predictions of the observed HM perturbation were made with poromechanical formulations. The fracturing phenomena and time evolution of the pore-pressure field due to skeleton viscosity were determined from generalized Perzyna viscoplastic theory (see references in Barnichon and Volckaert 2003). The negative-pore pressure that developed in the near zone of the opening due to the strong HM coupling in combination with a too-low support pressure imposed by a soft lining are the most likely explanations for the observed fracturing. As pointed out by the authors, the effects of potential fracturing on the overall performance of a high-level radioactive waste repository should remain limited due to the self-healing capacity of the Boom clay, although this requires further study.

The papers presented in this theme issue are by no means representative of all the research currently being undertaken about HM coupling. However, the papers presented do present an overview of HM coupling in geology and geotechnics. Our understanding of hydromechanical coupling in geology and its engineering applications is still at a relatively primitive stage. This has been expressed by several authors of this volume (Rutqvist and Stephansson 2003; Neuzil 2003). Important components of future advances of HM coupling in geology will be collection of data from hydromechanically critical settings such as the suggested deep drilling into the San
Andreas fault at Parkfield, California and by deep ocean drilling (Neuzil 2003). For the engineering applications, well defined and thoroughly conducted experiments in underground research stations or surface test sites in combination with coupled HM modeling will continue to help us make progress (Rutqvist and Stephansson 2003; Alonso and Gens2003).

Keywords Hydromechanics · Pore pressure · Rock mechanics $\cdot$ Rock deformation $\cdot$ Topical reviews

\section{References}

Alonso EE, Gens A, Delahaye CH (2003) Influence of rainfall on the deformation and stability of a slope in overconsolidated clays. A case study. Hydrogeol J DOI 10.1007/s10040-0020245-1

Barnichon J-D, Volckaert G (2003) Observations and predictions of hydromechanical coupling effects in the Boom clay (Mol URL, Belgium). Hydrogeol J DOI 10.1007/s10040-002-0240-6

Gudmundsson A, Gjesdal O, Brenne SL, Fjeldskaar I (2003) Effect of linking up of discontinuities on fracture growth and groundwater transport. Hydrogeol J DOI 10.1007/s10040-0020238-0

Heiland J (2003) Laboratory testing of coupled hydromechanical processes during rock deformation. Hydrogeol J DOI 10.1007/s10040-002-0236-2

Lewis RW, Makurat A, Pao WKS (2003) Fully-coupled modeling of seabed subsidence and reservoir compaction of North Sea oil fields. Hydrogeol J DOI 10.1007/s10040-002-0239-Z

Morin RH, WZ Savage (2003) Effects of crustal stresses on fluid transport in fractured rock: case studies from the northeast and southwest USA. Hydrogeol J DOI 10.1007/s10040-0020235-3

Neuzil CE (2003) Hydromechanical coupling in geologic processes. Hydrogeol J DOI 10.1007/s10040-002-0230-8

Rutqvist J, O Stephansson (2003) The role of hydromechanical coupling in fractured rock engineering. Hydrogeol J DOI 10.1007/s10040-002-0241-5

Woith H, Wang R, Milkereit C, Zschau J, Maiwald U, Pekdeger A (2000) Heterogeneous response of hydrogeological systems to the Izmit and Duzce (Turkey) earthquakes of 1999. Hydrogeol J DOI 10.1007/s10040-002-0244-2

Zangerl C, Eberhardt E, Loew S (2003) Ground settlement above tunnels in fractured crystalline rock: Numerical analysis of coupled hydromechanical mechanisms. Hydrogeol J DOI $10.1007 /$ s10040-002-0234-4 